\title{
PENGARUH HIDE POISON DAN FORMALIN TERHADAP SIFAT KULIT DALAM PENGAWETAN KULIT KAMBING SECARA DIKERINGKAN
}

Oleh

Ign. Sunaryo, Widari dan P.E. Suryaningsih *)

\section{ABSTRACT}

The objective of this study is to know the effect of hide poison and formaine in the dried curing of goat skin. This study used 119 goat skins that were devided inio seven groups of curing. Each group consisted of 17 goat skins. Those groups were : 3 groups of dried curing by hide poison of $0,1 \%, 0,3 \%$ and $0,5 \% ; 3$ groups of dried curing by formaline of $1 \%$, $3 \%$ and $5 \%$; and 1 group of dried curing without any preservation agent as control. After having stored for about 4 months, those skins then to be analized. Physical and chemical analysis were carried out to evaluate the quality of the skin. Completely randomized design by Duncan's test was used to analyze the data. Based on this statistical analysis we can know that : the effect of hide poison in the dried curing of goat skins was the best. The quality of goat skins that were cured by hide poison was as follows : - the average tensile strength was the highest $(886,30 \mathrm{~kg} / \mathrm{Cm} 2)$, - the average of stretch was the lowest $(14,50 \%)$, - the average of hardness was the highest $(201,90 \mathrm{~kg} / 2,54 \mathrm{Cm})$, - the water content was the lowest $(20 \%)$, and the damage was the smallest $(10 \%)$.

* Balai Besar Penelitian dan Pengembangan Industri Barang Kulit, Karet dan Plastik, Yogyakarta. 
Agar kulit kambing mentah tidak rusak sebelum diproses lebih lanjut, maka kulit perlu diawetkan. Hal ini penting mengingat kulit kambing merupakan salah satu produk ekspor non migas, baik dalam bentuk kulit jadi maupun barang jadi seperti jaket, sarung tangan dan lainlain. Prinsip pengawetan ialah dengan cara membersihkan kulit dari segala kotoran, lemak, sisa daging. Selanjutnya kadar air dalam kulit dikurangi sedemikian sehingga bakteri tidak berkembang.

Ada beberapa cara pengawetan kulit diantaranya ialah pengawetan secara dikeringkan dengan bahan pengawet. Perlunya bahan pengawet menurut Balai Penelitian Kulit 1962, dikarenakan pengawetan secara dikeringkan dengan sinar matahari saja kurang baik hasilnya, karena tidak tahan lama. Bahan pengawet menurut sifat dan daya mengawetnya dibedakan menjadi dua yakni : yang bersifat menyamak dan yang bersifat tidak menyamak. Bahan pengawet yang bersifat menyamak misalnya formalin. Sedangkan pengawet yang tidak menyamak misalnya hide poison atau arsen (Radiman, 1977).

Gustavson K.H. 1956 menerangkan bahwa formalin merupakan|bahan pengawet yang bersifat menyamak, karena bereaksi dengan kolagen, sehingga kulit, daging menjadi keras dan tidak mudah rusak. Walker J.F. 1953 menjelaskan bahwa formalin mempunyai daya antiseptik yang dapat membunuh bakteri, jamur serta yeast. Larutan yang mengandung $4 \%$ formalin cukup kuat untuk menghancurkan seluruh bentuk vegetatif dan kebanyakan bakteri. Menurut Scott untuk mendestruksi bakteri anthrax dalam bulu dapat dengan cara merendam kulit dalam larutan formalin selama 24 jam pada suhu $110^{\circ} \mathrm{F}$.

Selwood P.W. 1959, menjelaskan bahwa arsenik berasal dari bahasa Greek yang berarti arsenican artinya kuat. Senyawa arsen terutama ion dapat meracuni plasma sel. Oleh karena itu dapat untuk mengawetkan kulit karena menghambat pertumbuhan mikrobia. Menurut Radiman 1977, arsen dapat dipakai dalam dua bentuk yakni : sebagai arsen trioksida $\left(\mathrm{As} 2 \mathrm{O}_{3}\right)$ dan sebagai natrium arsenik $\left(\mathrm{NaAs} \mathrm{Q}_{2}\right)$. Natrium arsenik merupakan larutan yang cukup pekat dan dalam perdagangan dikenal sebagai hide poison, digunakan dalam pengawetan kulit. Penggunaan natrium arsenat menurit Balai Penelitian Kulit 1962 ialah $\pm 0,3 \%$ dengan lama perendaman berkisar antara $5-10$ menit.

Sifat kulit dipengaruhi juga oleh air yang terikat erat pada serat kolagen. Sedang banyaknya air yang diserap kulit dipengaruhi oieh suhu, kelembaban dan prosentase substansi kulit (kolagen). O'Flaherty F.W.T. 

kan Kanagy dan kawan-kawan 1978, melaporkan bahwa nilai kuat tarik kulit meningkat karena pengaruh suhu dan berkurang oleh adanya air. Walau kerusakan kulit dapat dihindari dengan pengawetan, tetapi menurut Gustavson K.H. 1956, pengawetan yang salah justru akan merusak kulit. Oleh karena itulah penelitian ini perlu dilaksanakan untuk mengetahui perbedaan pengaruh hide poison dan formalin dalam pengawetan kulit kambing secara dikeringkan terhadap sifat fisis (kekuatan tarik, kemuluran, kekakuan, kekuatan bengkuk) dan sifat khemis (kadar air) maupun sifat kulit berdasarkan pengamatan organoleptis.

\section{BAHAN DAN METODA}

B a ha n : - Kulit kambing sebanyak 119 lembar, berat rata-rata $1 \mathrm{~kg} / \mathrm{lb}$.

- Pengawet : formalin dan hide poison

A l a t : - Pisau buang daging

- Ember plastik

- Gelas ukur

- Thermometer

- papan pentangan

- tang

- drum penyamak

- pengukur kelembaban

- Kulit kambing 119 lembar dikélompokkan menjadi 7 kelompok masing-masing terdiri dari 17 lembar. Kelompok tersebut ialah :

a. 3 kelompok pengawetan dengan hide poison $0,1 \%$; $0,3 \%$ dan $0,5 \%$.

b. 3 kelompok pengawetan dengan formalin $1 \%, 3 \%$ dan $5 \%$.

c. 1 kelompok tanpa bahan pengawet sebagai kontrol.

- Setiap kelompok pengawetan kulit disesek, dicuci dan dietus selama \pm 15 menit. Selanjutnya kulit direndam \pm 10 menit untuk pengawetan dengan hide poison dan direndam selama 24 jam untuk pengawetan dengan formalin.

- Kulit dipentang, dijemur kemudian disimpan selama \pm 4 bulan.

- Analisa kulit secara fisika dan kimia dilakukan menurut Anonimus 1979.

Analisa data menggunakan rancangan acak lengkap dengan Duncan's Test.

\section{A. HASIL UJI PHISIS}

\section{Hasil uji kekuatan tarik (Tabel 1 dan 2)}

Tabel 1. Kekuatan tarik kulit kambing awet kering dengan hide poison dan formalin $(\mathrm{kg} / \mathrm{Cm} 2)$.

\begin{tabular}{c|c|c|c|c|c|c|c}
\hline \hline \multirow{2}{*}{ No. } & \multicolumn{3}{|c|}{ HIDE POISON } & \multicolumn{3}{c|}{ FORMALIN } & \multirow{2}{*}{ KON- } \\
\cline { 2 - 7 } & $0,5 \%$ & $0,3 \%$ & $0,1 \%$ & $5 \%$ & $3 \%$ & $1 \%$ & TROL \\
\hline & & & & & & & \\
1. & 880,30 & 714,65 & 746,13 & 264,77 & 347,41 & 522,49 & 733,34 \\
2. & 905,02 & 929,17 & 742,74 & 392,86 & 535,72 & 629,17 & 711,93 \\
3. & 808,34 & 772,47 & 695,71 & 203,07 & 403,31 & 529,56 & 712,28 \\
4. & 851,80 & 589,97 & 780,30 & 226,64 & 552,82 & 461,36 & 769,57 \\
5. & 986,02 & 756,52 & 693,18 & 369,45 & 484,03 & 589,39 & 921,48 \\
\hline
\end{tabular}

Tabel 2. Analisa varians kekuatan tarik

\begin{tabular}{l|r|r|r|r}
\hline SUMBER VARIASI & \multicolumn{1}{|c|}{ df } & \multicolumn{1}{c|}{ SS } & \multicolumn{1}{c|}{ MS } & \multicolumn{1}{c}{ F } \\
\hline Perlakuan & 6 & 1297079,64 & 216179,94 & \\
Error & 28 & 190131,38 & 6790,41 & $31,84 * *$ \\
\hline
\end{tabular}

Dari Tabel 1 dapat diketahui bahwa nilai tertinggi kekuatan tarik : $886,29 \mathrm{~kg} / \mathrm{Cm} 2$ terdapat pada kulit yang diawet dengan hide poison $0,5 \%$. Sedangkan nilai rata-rata kekuatan tarik dari yang tertinggi ke yang terendah berturut-turut adalah : - kulit yang diawet dengan hide poison : 790,15 kg/Cm2; - kontrol : $762,72 \mathrm{~kg} / \mathrm{Cm} 2$; - kulit yang diawet dengan formalin : $434,12 \mathrm{~kg} / \mathrm{Cm} 2$. Ada kecenderungan rilai kekuatan tarik semakin kecil dengan semakin kecilnya konsentrasi hide poison. Sebaliknya kulit yang diawet dengan formalin nilai kekuatan tariknya semakin kecil dengan semakin besarnya konsentrasi perlakuan. Hasil analisa statistik dengan analisa varians, ternyata tidak ada perbedaan nyata $(P \leqslant 0,05)$ antara kontrol dengan kulit yang diawet dengan hide poison. Tetapi berbeda sangat nyata $(\mathrm{P} \leqslant 0,01)$ dengan kulit yang diawet dengan formalin. 


\section{Hasil uji kemuluran (Tabel 3 dan 4)}

Tabel 3. Kemuluran kulit kambing awet kering dengan hide poison dan formalin (\%)

\begin{tabular}{|c|c|c|c|c|c|c|c|}
\hline \multirow{2}{*}{ No. } & \multicolumn{3}{|c|}{ HIDE POISON } & \multicolumn{3}{|c|}{ FORMALIN } & \multirow{2}{*}{$\begin{array}{l}\text { KON- } \\
\text { TROL }\end{array}$} \\
\hline & 0,5 & 0,3 & 0,1 & 5 & 3 & 1 & \\
\hline 1. & 17,00 & 16,50 & 14,00 & 17,00 & 21,00 & 17,50 & 18,00 \\
\hline 2. & 14,00 & 15,00 & 13,00 & 22,00 & 17,00 & 17,30 & 20,00 \\
\hline 3. & 15,50 & 14,50 & 11,00 & 21,50 & 20,00 & 21,00 & 8,00 \\
\hline 4. & 15,00 & 12,00 & 12,00 & 17,00 & 18,50 & 22,50 & 22,00 \\
\hline 5. & 16,00 & 17,50 & 14,50 & 16,00 & 18,00 & 16,00 & 22,00 \\
\hline
\end{tabular}

Tabel 4. Analisa varians kemuluran kulit kambing

\begin{tabular}{l|r|r|r|r}
\hline \hline SUMBER VARIASI & df & SS & MS & \multicolumn{1}{c}{ F } \\
\hline Perlakuan & 6 & 193,99 & 32,33 & $4,91 * *$ \\
Error & 28 & 184,40 & 6,59 & \\
\hline
\end{tabular}

** berbeda sangat nyata $(\mathrm{P} \leqslant 0,01)$.

Dari tabel tersebut dapat diketahui bahwa nilai kemuluran pada kulit yang diawet dengan hide poison ada kecenderungan semakin meningkat dengan semakin besarnya konsentrasi hide poison. Sebaliknya kulit yang diawet dengan formalin, nilai kemulurannya cenderung menurun dengan semakin besarnya dosis formalin. Nilai terrendah terdapat pada kulit yang diawet dengan hide poison : 14,50 $\pm 1,89 \%$. Nilai rata-rata kemuluran dari yang tertinggi ke yang terrendah berturut-turut adalah - kulit yang diawet dengan formalin $18,83 \%$; - kontrol 16,8\%; - kulit yang diawet dengan hide poison $14,5 \%$. Hasil uji statistik dengan analisa varians ternyata tidak ada beda nyata $(P \leqslant 0,05)$ antara kontrol dengan kulit yang diawet dengan hide poison $0,5 \%$ dan $0,3 \%$. Tetapi berbeda sangat nyata $(\mathrm{P} \leqslant 0,01)$ antara kontrol dengan kulit yang diawet dengan hide poison $0,1 \%$.

\section{Hasil uji kekakuan (Tabel 5 dan 6)}

Tabel 5. Hasil uji kekakuan kulit kambing awet kering dengan hide poison dan formalin $(\mathrm{kg} / 2,54 \mathrm{Cm})$.

\begin{tabular}{l|r|r|r|r|r|r|r}
\hline \multirow{2}{*}{ No. } & \multicolumn{3}{|c|}{ HIDE POISON } & \multicolumn{3}{c|}{ FORMALIN } & \multirow{2}{*}{$\begin{array}{c}\text { KON- } \\
\text { TROL }\end{array}$} \\
\cline { 2 - 7 } & $0,5 \%$ & $0,3 \%$ & $0,1 \%$ & $5 \%$ & $3 \%$ & $1 \%$ & \\
\hline & & & & & & & \\
1. & 170,99 & 106,54 & 159,08 & 63,20 & 80,07 & 64,45 & 137,05 \\
2. & 155,04 & 193,29 & 193,69 & 68,05 & 35,12 & 88,19 & 170,21 \\
3. & 89,57 & 149,29 & 203,37 & 54,09 & 77,72 & 86,49 & 181,85 \\
4. & 171,81 & 161,08 & 203,37 & 67,01 & 93,63 & 74,35 & 126,39 \\
5. & 422,11 & 141,08 & 126,39 & 71,44 & 106,46 & 113,99 & 184,01 \\
\hline
\end{tabular}

Tabel 6. Analisa varians kekakuan kulit kambing

\begin{tabular}{l|r|r|r|c}
\hline \hline SUMBER VARIASI & df & \multicolumn{1}{c|}{ SS } & MS & F \\
\hline Perlakuan & 6 & 87852,39 & 14642,07 & $5,06 * *$ \\
Error & 28 & 80958,19 & 2891,36 & \\
\hline
\end{tabular}

** berbeda sangat nyata $(\mathrm{P} \leqslant 0,01)$.

Nilai kekakuan kulit terendah $64,76 \pm 6,65 \mathrm{~kg} / 2,54 \mathrm{Cm}$, terdapat pada kulit yang diawet dengan formalin. Nilai kekakuan rata-rata dari yang tertinggi ke yang terendah berturut-turut adalah : - kulit yang diawet dengan hide poison $176,4 \mathrm{~kg} / 2,54 \mathrm{Cm}$; - kontrol : $159,90 \mathrm{~kg} / 2,54 \mathrm{Cm}$; kulit yang diawet dengan formalin $76,28 \mathrm{~kg}$ / $2,54 \mathrm{Cm}$. Hasil analisa statistik menunjukkan tidak ada perbedaan yang nyata $(P \leqslant 0,05)$ antara kontrol dengan kulit yang diawet dengan hide poison. Tetapi berbeda sangat nyata $(P \leqslant 0,01)$ antara kontrol dengan kulit yang diawet dengan formalin.

4. Hasil uji kekuatan bengkuk kulit kambing awet kering dengan hide poison dan formalin.

Dari hasil uji kekuatan bengkuk dapat diketahui bahwa lebih dari separoh $(64,30 \%)$, kulit pecah sewaktu diuji. Sedang 35,7\% sisanya masih menunjukkan hasil yang baik. tidak pecah, terutama kulit yang diawet dengan formalin. 


\section{B. HASIL UJI KHEMIS}

Penguji kimiawi yang dilakukan adalah pengujian kadar air. Hasil uji kadar air disajikan dalam Tabel 7 dan 8.

Tabel 7. Kadar air kulit kambing awet kering dengan hide poison dan formalin $(\%)$

\begin{tabular}{c|c|c|c|c|c|c|c}
\hline \hline \multirow{2}{*}{ No. } & \multicolumn{3}{|c|}{ HIDE POISON } & \multicolumn{3}{c|}{ FORMALIN } & \multirow{2}{*}{$\begin{array}{c}\text { KON- } \\
\text { TROL }\end{array}$} \\
\cline { 2 - 7 } & $0,5 \%$ & $0,3 \%$ & $0,1 \%$ & $5 \%$ & $3 \%$ & $1 \%$ & \\
\hline 1. & 20,00 & 19,99 & 20,42 & 21,99 & 20,99 & 20,99 & 21,99 \\
2. & 20,00 & 21,00 & 20,99 & 21,01 & 20,99 & 21,02 & 22,00 \\
3. & 20,00 & 20,00 & 20,90 & 21,00 & 20,90 & 21,00 & 21,40 \\
\hline
\end{tabular}

Tabel 8. Analisa varians kadar air kulit kambing

\begin{tabular}{l|r|c|c|c}
\hline \hline SUMBER VARIASI & df & SS & MS & F \\
\hline Perlakuan & 6 & 6,47 & 1,08 & $8,31^{* *}$ \\
Error & 14 & 1,75 & 0,13 & \\
\hline
\end{tabular}

** berbeda sangat nyata $(P \leqslant 0,01)$

Dari tabel tersebut dapa ciketahui bahwa kadar air dari yang tertinggi ke yang terendah adalah : kontrol $21,79 \%$; kulit yang diawet dengan formalin 21,09\%; - kulit yang diawet dengan hide poison $20,3 \%$. Kadar air terendah terdapat pada kulit yang diawet dengan hide poison : $20,82 \%$. Dari hasil uji statistik ternyata ada beda sangat nyata $(P \leqslant 0,01)$ antara kontrol dengan kulit yang diawet dengan formalin $1 \%$ dan $3 \%$ dan juga dengan kulit yang diawet dengan hide poison.

\section{HASIL PENGAMATAN ORGANOLEPTIS}

Setelah \pm 4 bulan dalam penyimpanan ternyata kulit sudah mengalami kerusakan. Kerusakan terutama oleh serangga jenis kumbang Dermestes. Kerusakan kulit yang diawet dengan hide poison sekitar 10 $\%$, di daerah leher dan ekor. Kerusakan kulit yang diawet dengan formalin sekitar $13 \%$ juga didaerah leher dan ekor. Kerusakan terbesar terdapat pada kontrol yakni sekitar $75 \%$ baik oleh serangga maupun jamur Aspergillus sp. dan Penicellium sp.

\section{PENGAMATAN SUHU DAN KELEMBABAN DALAM RUANG PE- NYIMPANAN}

Selama penyimpanan suhu dalam ruang penyimpanan adalah normal yakni $27^{\circ} \mathrm{C}$. Sedangkan kelembaban rata-rata adalah $77 \%$.

\section{KESIMPULAN}

Berdasarkan hasil uji dan analisa statistik dapat diambil kesimpulan : pengawetan kulit kambing secara dikeringkan dapat menggunakan hide poison $0,1 \%, 0,3 \%$ dan $0,5 \%$, karena sifat kulitnya lebih baik dibanding pengawetan dengan formalin. Kualitas kulit yang diawet dengan hide poison mempunyai niiai rata-rata kekuatan tarik tertinggi : $886,30 \mathrm{~kg} / \mathrm{Cm} 2$, kemuluran terendah : $14,50 \%$, kekakuan tertinggi : $201,90 \mathrm{~kg} / 2,54 \mathrm{Cm}$, kadar air terendah : $20 \%$ dan kerusakan kulit terkecil : $10 \%$. 
Anonimus, 1970. Hasil-hasil seminar perkulitan. Seminar on hide and leather, B.P.K. Akademi Teknologi Kulit, Yogyakarta.

Anonimus, 1972. Teknik Pengawetan Kulit. Proyek Cess Pusat.

Anonimus, 1979. Mutu dan cara uji kulit boks. Badan Penelitian dan Pengembangan Industri, Departemen Perindustrian, Jakarta.

Aten, A.R.; F. Innes dan E. Knew, 1955. Flaying and curing of hides and skins as a rural industry. F.A.O. of the United Nations, Rome, Italy.

Balai Penelitian Kulit, 1962. Kaleidoscop kulit dari hewan hingga barang jadi. Course on flaying and curing, B.P.K. Yogyakarta.

Dirjen Peternakan, Deptan., 1978. Penataran pengawas rumah potong hewan seluruh Indonesia.

Gustavson, K.H. 1956. The chemistry and reactivity of collagen. Academic Press, Inc. Publisher. New York.

John, C. Bailar, Jr. et al. 1965. University Chemisiry. D.C. Hearth Company. Boston. USA.

Man, I. 1960. Rural tanning techniques. Ford and Agricultural Organization of the Limeted Nations, Rome.

O'Flaherty; F.W.J. Roddy and R.M. Lolbar, 1978. The chemistry and technology of leather. Vol. IV. Robert E. Kringer Publishing Company, Hutingtow, New York.

Radiman, 1977. Peningkatan taksodermi. Laporan Proyek B.P.K. Departemen Perindustrian, Yogyakarta.

Selwood, P.W. 1959. General chemistry. Holt, Renehart and Winston, Inc. USA.

Walker, J.F. 1953. Formalidehide. Book Devision Reinhold Publishing Corporation, New York. USA.

Wikantadi, B. 1972. Beberapa cara mengawetkan kulit mentah. Biro Pengabdian Masyarakat. Universitas Gadjah Mada, Yogyakarta. 